\title{
New Insights from the Bitcoin Futures Market
}

\author{
Yimiao Chen, Leh-Chyan So* \\ Department of Quantitative Finance, National Tsing Hua University, Taiwan \\ Email: *lcso@mx.nthu.edu.tw
}

How to cite this paper: Chen, Y. M., \& So, L.-C. (2020). New Insights from the Bitcoin Futures Market. Modern Economy, 11, 1463-1475

https://doi.org/10.4236/me.2020.118104

Received: July 6, 2020

Accepted: August 10, 2020

Published: August 13, 2020

Copyright (c) 2020 by author(s) and Scientific Research Publishing Inc. This work is licensed under the Creative Commons Attribution International License (CC BY 4.0).

http://creativecommons.org/licenses/by/4.0/

\section{(c) (i) Open Access}

\begin{abstract}
Recently, cryptocurrencies have drawn considerable attention from investors around the world. Such digital assets have also raised numerous hot issues in academic fields. Among them, Bitcoin is the most well-known and most notorious. After it was created in 2009, Bitcoin kept rising in price and reached its peak in late 2017. After that, it plunged dramatically. Coincidentally, Bitcoin futures also launched in December 2017. We are curious about the role Bitcoin futures play in the Bitcoin market. In this study, we investigate the relationship between Bitcoin and Bitcoin futures. First, we compare the optimal hedge ratios using three different hedge strategies, the naïve hedge, the ordinary least squares (OLS) method, and dynamic hedging with the bivariate BEKK-GJR-GARCH model. Dynamic hedging is the most effective of the three methods; the level of risk reduction is around 59\%. Then we test whether the volatility of Bitcoin would be significantly different before and after Bitcoin futures (BTC) launched. Our results support the hypothesis.
\end{abstract}

\section{Keywords}

Hedging, Hedge Ratios, Bitcoin, Bitcoin Futures, GARCH Model

\section{Introduction}

Investors worldwide, eager to have an exciting ride, have been fascinated by Bitcoin, the genesis cryptocurrency created in 2009. And for one decade, there has been no observable fading of the craze for Bitcoin, given the increasing trade volumes.

Although Bitcoin is notorious for its volatile price movement, when we look several years back at Bitcoin's history, we see that its price increased relatively steadily. However, during the critical year 2017, the price of Bitcoin skyrocketed from $\$ 1000$ in January to a record high of $\$ 20,000$ in December, as reported on the CoinDesk. Yet the price dropped dramatically by about 35\% in late December, a phenomenon generally believed to be the result of the strict regulation of 
Bitcoin trading announced by the South Korean government, influencing the world's third-largest cryptocurrency market. Then, during 2018, the Bitcoin market price continued decreasing to less than $\$ 4000$ by the end of the year.

Among others, the most popular issue with respect to Bitcoin is its diversification effect. Much recent research has been devoted to the diversification effect of Bitcoin incorporated into a portfolio with other financial assets. For example, Dyhrberg (2016) concluded that Bitcoin, similar to gold, could hedge against the Financial Times Stock Exchange Index and the US dollar. However, by testing stock indices, bonds, oil, gold, the general commodity index, and the US dollar index, Bouri, Molnár, Azzi, Roubaud, and Hagfors (2017) indicated that the hedging capability of Bitcoin could only be observed in some cases and might vary according to the data frequency. Responding to their findings, Kurka (2019) suspected the potential of Bitcoin as a diversifier against several traditional asset classes. He even raised a warning that market disturbances can transmit from Bitcoin to the traditional economy.

So the position of Bitcoin in risk management is controversial. Due to Bitcoin's high risk of being hacked as well as the lack of deposit insurance offered within banking systems, participating in the Bitcoin market has become a way of speculating. Thus, regardless of whether it is a safe haven for other financial assets, Bitcoin also needs a safe haven for its own risks.

At the moment when Bitcoin investors were experiencing their most exciting roller coaster ride, Bitcoin futures coincidentally launched in December 2017. We are curious about the role Bitcoin futures play in the Bitcoin market. Traditionally, futures are considered an innovative way of hedging volatile price movement in financial assets. Many studies have been conducted on various topics with respect to using different futures to hedge spots. For instance, Cecchetti, Cumby, and Figlewski (1988) used T-bond futures to hedge Treasury bonds. Baillie and Myers (1991) tested six different commodities futures hedges by using a bivariate GARCH model. Kroner and Sultan (1993) measured foreign currency futures hedges using dynamic methods. Park and Switzer (1995) also estimated stock index futures hedges using a bivariate GARCH model. Hung, Lee, and So (2005) estimated foreign-listed single-stock futures hedges using a bivariate GJR-GARCH model. However, few studies have been conducted on hedging with cryptocurrency futures. Corbet, Lucey, Peat, and Vigne (2018) investigated the effect of Bitcoin futures on hedging Bitcoin by using ordinary least squares hedging and naïve hedging strategies. By analyzing data from September 26, 2017, to February 22, 2018, they concluded that Bitcoin futures are not an efficient hedging tool. They also showed that the introduction of Bitcoin futures increased the volatility in the Bitcoin market.

As for the issue of the interrelationship between Bitcoin futures and spots, the literature is relatively inadequate, and the conclusions are inconsistent. Liu, Wan, Zhang, and Zhao (2019) proposed indicated that the launch of Bitcoin futures had a significantly negative effect on Bitcoin returns. Hattori and Ishida (2018), on the other hand, provided evidence to show that the negative influence 
of the introduction of Bitcoin futures could only be observed during a very short time; hence, they reasoned, Bitcoin futures were not to blame for the Bitcoin market crash in late 2017.

As the above discussions demonstrate, there are unresolved conflicts among researchers not only on the potential of Bitcoin futures in hedging Bitcoin but also on their influence on the Bitcoin spot market after their launch. In this study, we tried to clarify the relationship between Bitcoin and Bitcoin futures. First, we compared the optimal hedge ratios using three different hedge strategies, the naïve hedge, the ordinary least squares (OLS) method, and dynamic hedging with the bivariate BEKK-GJR-GARCH model. Our results showed that dynamic hedging is the most effective of the three methods, and the level of risk reduction is quite obvious, around $59 \%$. Then we tested whether the volatility of Bitcoin would have been significantly different before and after Bitcoin futures (BTC) launched. Our findings provided supporting evidence.

The remainder of this paper proceeds as follows: the data are described in Section 2; the methodology is presented in Section 3; the empirical results are analyzed in Section 4, and conclusions are given in Section 5.

\section{Data}

In late 2017, Bitcoin futures were launched on two exchanges. While the one with the symbol "XBT" opened for trading on the CBOE Futures Exchange, LLC on December 10, 2017, the other, with the symbol "BTC", followed on the CME Group on December 18, 2017. Although CBOE was the first exchange to launch Bitcoin futures, the exchange announced in March 2019 that it had stopped adding Bitcoin futures. In our paper, we decided upon Bitcoin futures on the CME Group as our research object, partly because its trading volume is larger and partly because of its underlying index, the CME CF Bitcoin Reference Rate (BRR), is relatively transparent.

The BRR was created by the CME Group and Crypto Facilities Ltd. on November 14, 2016. Initially, BRR was calculated from six exchanges, Bitstamp, GDAX, itBit, Kraken, Bitfinex, and Okcoin. However, Bitfinex was removed on April 18, 2017, followed by the removal of Okcoin on April 20, 2017. Now the BRR is calculated from four exchanges. The BRR is a daily reference rate of one bitcoin, which is denominated in US dollars at 4 p.m. London time ${ }^{1}$.

The BTC was listed on December 18, 2017. The CME Group Bitcoin futures contract unit is five bitcoins, defined by BRR ${ }^{2}$.

Data regarding the BRR and BTC, whose trading code is BTCc1, were obtained from the Thomson Reuters Eikon (Eikon) database. To implement the first part of our study on the effectiveness of hedging with Bitcoin futures on its ${ }^{1}$ Refer to the following website for more details: https://www.cmegroup.com/education/courses/introduction-to-bitcoin/introduction-to-bitcoin-refe rence-rate.html.

${ }^{2}$ Refer to the following website for more details: https://www.cmegroup.com/trading/bitcoin-futures.html. 
spot, we unified the data period from December 18, 2017, to April 25, 2019. To make the data of BRR and BTC comparable, we also removed the single data of BRR or BTC if we could not obtain its corresponding data.

Data regarding Bitcoin prices in the Bitstamp, Coinbase, itBit, and Kraken exchanges were collected from the Bloomberg database from their beginning to April 25, 2019. We also dealt with the missing data problem. Figure 1 demonstrates the patterns of Bitcoin prices from these four exchanges. It shows that Bitcoin prices have a turning point around late 2017 and early 2018. The prices reached a peak in late 2017 . Then the prices dropped dramatically in late December and continued decreasing by the end of the year.

Figure 2 illustrates the returns from the four different exchanges. It shows that the Bitcoin returns have the phenomenon of volatility clustering during several critical events in Bitcoin history.

\section{Methodology}

\subsection{Hedge Ratios}

We compared the performance of three different hedging strategies.
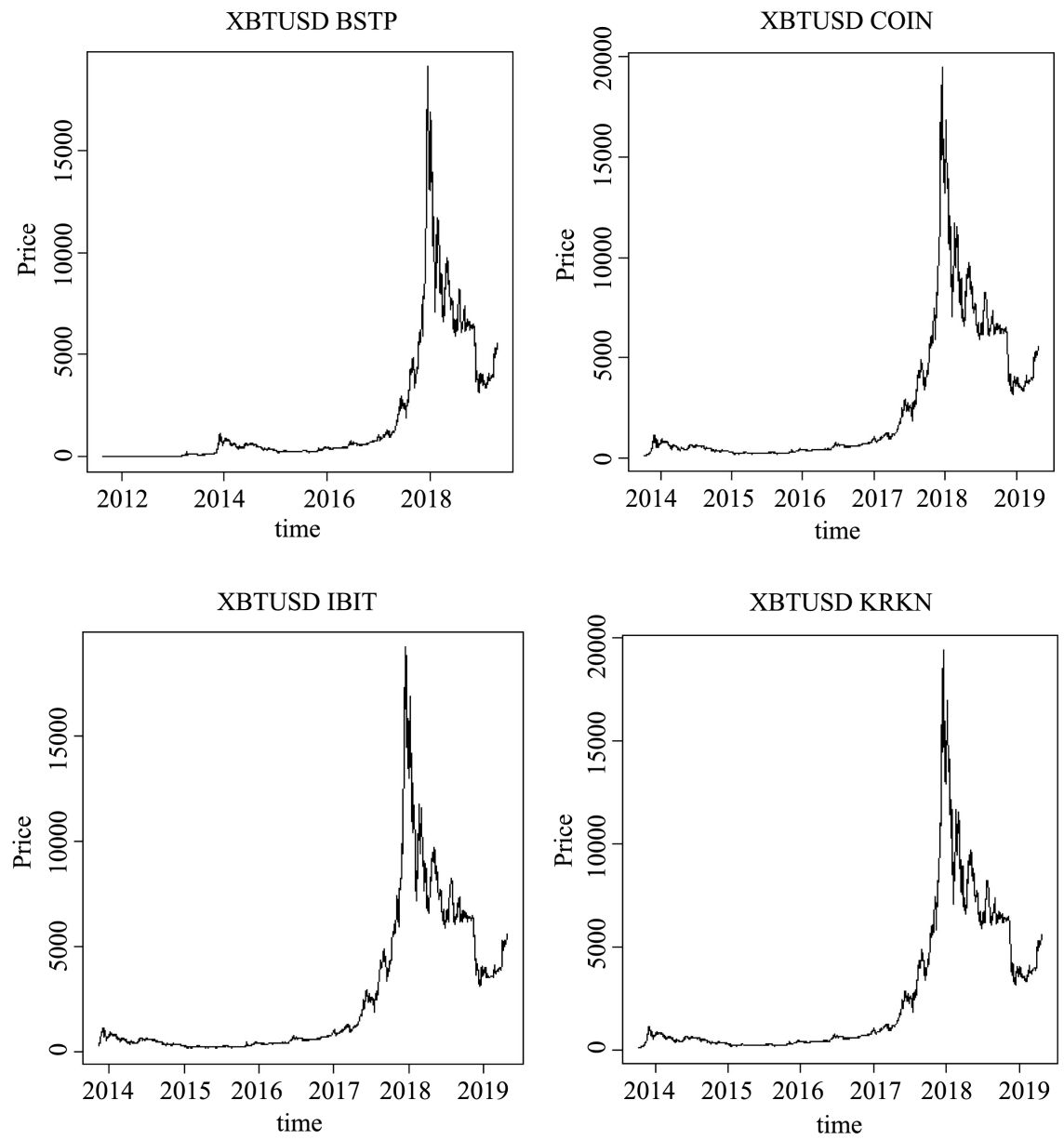

Figure 1. Bitcoin prices from the four exchanges. (Bitstamp, BSTP; Coinbase, COIN; itBit, IBIT; Kraken, KRKN). 



Figure 2. Bitcoin returns from the four exchanges. (Bitstamp, BSTP; Coinbase, COIN; itBit, IBIT; Kraken, KRKN).

The naïve hedge ratio is the simplest hedging method; it is also called the perfect hedge. The naïve hedge means that the hedge ratio is set as one. The investors buy (sell) the one spot position and sell (buy) the one futures position.

The minimum variance hedging strategy is the most popular strategy. The investors buy (sell) the one spot position and sell (buy) $h$ futures positions. According to Hung, Lee, and So (2005), $h$ can be solved by the following steps.

Define

$$
\Delta s_{t}=s_{t+1}-s_{t}
$$

the change in the underlying price, $s$, during the period of the hedge:

$$
\Delta f_{t}=f_{t+1}-f_{t}
$$

the change in futures price, $f$, during the period of the hedge:

$$
\Delta P_{t}=\Delta s_{t}-h \Delta f_{t} ;
$$

and the change in hedged portfolio during the period of hedge, with hedge ratio $h$.

Our main task is to minimize the variance of the change in the hedged portfolio by choosing the optimal hedge ratio, $h^{*}$ : 


$$
\operatorname{Var}(\Delta P)=\operatorname{Var}(\Delta s)-2 h \operatorname{Cov}(\Delta s, \Delta f)+h^{2} \operatorname{Var}(\Delta f)
$$

$h^{*}$ can be solved by setting the first order condition equal to zero:

$$
h^{*}=\frac{\operatorname{Cov}(\Delta s, \Delta f)}{\operatorname{Var}(\Delta f)} .
$$

Equally, we can regress the changes in spot price on the changes in futures price by using the ordinary least squares method (OLS):

$$
\Delta s_{t}=\alpha+\beta \Delta f_{t}+e_{t} .
$$

Third, we used the bivariate BEKK-GJR-GARCH model to catch the dynamic hedge ratios. According to Aftab, Beg, Sun, and Zhou (2019), we built up our bivariate BEKK-GJR-GARCH model as follows.

Define

$$
q_{t}=\left(\Delta s_{t}, \Delta f_{t}\right)^{\prime}=\left(q_{1 t}, q_{2 t}\right)^{\prime}, t=1,2,3, \cdots, T
$$

the vector of $\Delta s_{t}$ and $\Delta f_{t}$ at time $t$.

We assume that the multivariate version of changes in spot and futures prices is represented by a vector autoregression of order $p$, conditional on information at time $t, \mathcal{F}_{t-1}$ :

$$
q_{t} \mid \mathcal{F}_{t-1}=\Phi_{0}+\sum_{l=1}^{p} \Phi(l) q_{t-l}+\varepsilon_{t} .
$$

The mean equation is

$$
E\left(q_{t} \mid \mathcal{F}_{t-1}\right)=\Phi_{0}+\sum_{l=1}^{p} \Phi(l) q_{t-l}=\mu_{t},
$$

where

$$
\Phi(l)=\left(\Phi_{i j}(l)\right)
$$

is the $2 \times 2$ coefficient matrix of the lagged variables.

Define the symmetric matrix $G_{t}=\left[\begin{array}{ll}g_{11, t} & g_{12, t} \\ g_{21, t} & g_{22, t}\end{array}\right]$ of order $2 \times 2$ representing the conditional variance-covariance matrix of innovations:

$$
G_{t}=E\left(\varepsilon_{t} \varepsilon_{t}^{\prime} \mid \mathcal{F}_{t-1}\right)=E\left(q_{t}-E\left(q_{t}\right)\right)\left(q_{t}-E\left(q_{t}\right)\right)^{\prime} \mid \mathcal{F}_{t-1} .
$$

To capture the asymmetric transmission effect of bad news and good news, we define a dummy

$$
D_{i t-1}=\left\{\begin{array}{l}
1 \text { if } \varepsilon_{i t-1}<0 \text { bad news } \\
0 \text { if } \varepsilon_{i t-1} \geq 0 \text { good news }
\end{array} .\right.
$$

If $\varepsilon_{i t-1} \geq 0$, then the dummy variable is 0 , which represents the good news. In contrast, if $\varepsilon_{i t-1}<0$, then the dummy variable is 1 , which represents the bad news.

In this way, the bivariate BEKK-GJR-GARCH model can be described as

$$
G_{t}=C^{\prime} C+A^{\prime} \varepsilon_{t-1} \varepsilon_{\mathrm{t}-1}^{\prime} A+B^{\prime} G_{t-1} B+\Gamma^{\prime} D_{i t-1} \varepsilon_{t-1} \varepsilon_{t-1}^{\prime} \Gamma .
$$

After estimating the bivariate BEKK-GJR-GARCH model, we collect the estimated values of the conditional correlation: 


$$
\rho_{12, t}=\frac{g_{12, t}}{\sqrt{g_{11, t}} \sqrt{g_{22, t}}} .
$$

The dynamic hedge ratios are obtained by

$$
\varphi_{t}=\frac{\operatorname{Cov}_{t-1}\left(\Delta f_{t}, \Delta s_{t}\right)}{\operatorname{Var}_{t-1}\left(\Delta f_{t}\right)}=\frac{\rho_{12, t} \sqrt{g_{11, t} g_{22, t}}}{g_{22, t}} .
$$

Finally, we compare the hedging performance of these three strategies in terms of the level of $\operatorname{Var}\left(\Delta s_{t}-h_{t} \Delta f_{t}\right)$, following Kroner and Sultan (1993) and Hung, Lee, and So (2005); $h_{t}$ varies according to different methods: unity for the naïve hedge, a constant optimal hedge ratio for the minimum variance hedge, and time-varying hedge ratios for the bivariate BEKK-GJR-GARCH model.

\subsection{Impact of Bitcoin Futures Launch on Bitcoin Market}

In this subsection, we investigate whether the volatility of Bitcoin price returns would have been changed after the Bitcoin futures (BTC) launched.

First, we estimate the daily returns of Bitcoin:

$$
r_{t}=\ln \frac{p_{t}}{p_{t-1}},
$$

where $p_{t}$ and $p_{t-1}$ are the Bitcoin prices at time $t$ and $t-1$, respectively.

Compared with various ARCH models, GARCH $(1,1)$ has been proven to perform best on estimating conditional volatility (Akgiray, 1989). Hence, we assume that the conditional variance of the daily returns follows the GARCH $(1,1)$ :

$$
h_{t}=c_{0}+a r_{t-1}^{2}+b h_{t-1},
$$

where $h_{t}$ is the conditional variance of Bitcoin daily return at time $t, h_{t-1}$ is the conditional variance of Bitcoin daily return at time $t-1$, and $r_{t-1}^{2}$ is the daily squared return of Bitcoin at time $t-1$.

Then we estimate the parameter values of $a$ and $b$ in Equation (17) for three periods: one is the period before the BRR launched, another is after BRR launched till BTC was listed, which we call the transition period, and the other is the period after BTC was listed. By applying the statistical method called two-sample $t$ test, proposed by Harnett and Soni (1991), Rahman (2001) and Hung and So (2009), we studied on whether the volatilities of underlying returns would change after the introduction of their derivatives.

The $t$ statistic is

$$
t_{d}=\frac{\left(\bar{x}_{\text {before }}-\bar{x}_{\text {after }}\right)-\left(\mu_{\text {before }}-\mu_{\text {after }}\right)}{\sqrt{\left(\frac{\left(n_{\text {before }}-1\right) s_{\text {before }}^{2}+\left(n_{\text {after }}-1\right) s_{\text {after }}^{2}}{n_{\text {before }}+n_{\text {after }}-2}\right)\left(\frac{1}{n_{\text {before }}}+\frac{1}{n_{\text {after }}}\right)}}
$$

where $n_{\text {before }}$ and $n_{\text {after }}$ are sample observations, $s_{\text {before }}^{2}$ and $s_{\text {after }}^{2}$ are sample variances, $\bar{x}_{\text {before }}$ and $\bar{x}_{\text {after }}$ are sample means, and $\mu_{\text {before }}$ and $\mu_{\text {after }}$ are population means. The statistic follows a $t$-distribution with a degree of freedom of 
$\left(n_{\text {before }}+n_{\text {after }}-2\right)$. We investigated cases of $a$ and $b$ to discuss whether the volatility of Bitcoin returns would change significantly from period to period.

\section{Empirical Results}

Table 1 shows the descriptive statistics for the data of BRR and BTC and the changes in the indices from December 18, 2017, to April 25, 2019. From these 333 observations, it is observed that the underlying price and the futures price share similarity in most of the statistics. Their means are around 6900. Their standard deviations and their range are about 2900 and 16,000, respectively. The average trading volume of BTC is 3636 . The changes in BRR and BTC tend to be negatively skewed and have high kurtosis.

As Table 2 indicates, the constant optimal hedge ratio is 0.84069 . This means that one unit of the BRR should be hedged by selling short 0.84069 units of BTC.

Figure 3 displays the volatile pattern of the dynamic hedge ratios, comparing with the strict line of the constant hedge ratio.

The hedging performance and risk reduction of these three strategies are summarized in Table 3 . The performance of the hedging in these cases is compared by computing the variances of the hedged portfolio when using different hedging methods. Among them, the variance of the naïve hedge, 92,114, is the highest, while the variance of the dynamic hedge using the bivariate BEKK-GJR-GARCH model, 87,201, is the lowest. The hedging effectiveness is

Table 1. Price, volume and the changes of spot and futures for BRR and CME Group Bitcoin futures (BTC).

\begin{tabular}{cccccc}
\hline & \multicolumn{2}{c}{ BRR } & \multicolumn{2}{c}{ CME Group Bitcoin Futures (BTC) } \\
\cline { 2 - 6 } & Price (USD) & $\Delta s_{t}$ & Price (USD) & $\Delta f_{t}$ & Volume \\
\hline Mean & 6892.876 & -40.35181 & 6887.473 & -40.99398 & 3635.532 \\
Standard deviation & 2907.558 & 462.6823 & 2937.894 & 423.0727 & 2837.431 \\
Median & 6465.84 & -7.57 & 6460 & -5 & 2951 \\
Min & 3239.22 & -2879.8 & 3145 & -2785 & 299 \\
Max & $18,842.53$ & 2880.33 & 19100 & 1715 & 21775 \\
Range & $15,603.31$ & 5760.13 & 15955 & 4500 & 21476 \\
Skewness & 1.245295 & -0.2108436 & 1.264137 & -1.054242 & 2.221384 \\
Kurtosis & 1.99217 & 14.68115 & 2.074758 & 8.624834 & 7.5981 \\
Standard Error & 159.3332 & 25.39299 & 160.9956 & 23.21913 & 155.4902 \\
Observations & 333 & 332 & 333 & 332 & 333 \\
\hline
\end{tabular}

Data period is from $2017 / 12 / 18$ to $2019 / 04 / 25$.

Table 2. Constant optimal hedge ratio $\Delta s_{t}=\alpha+\beta \Delta f_{t}+e_{t}$.

\begin{tabular}{cc}
\hline Name & CME Group Bitcoin Futures (BTC) \\
\hline Constant optimal hedge ratio $(\beta)$ & 0.84069 \\
\hline
\end{tabular}




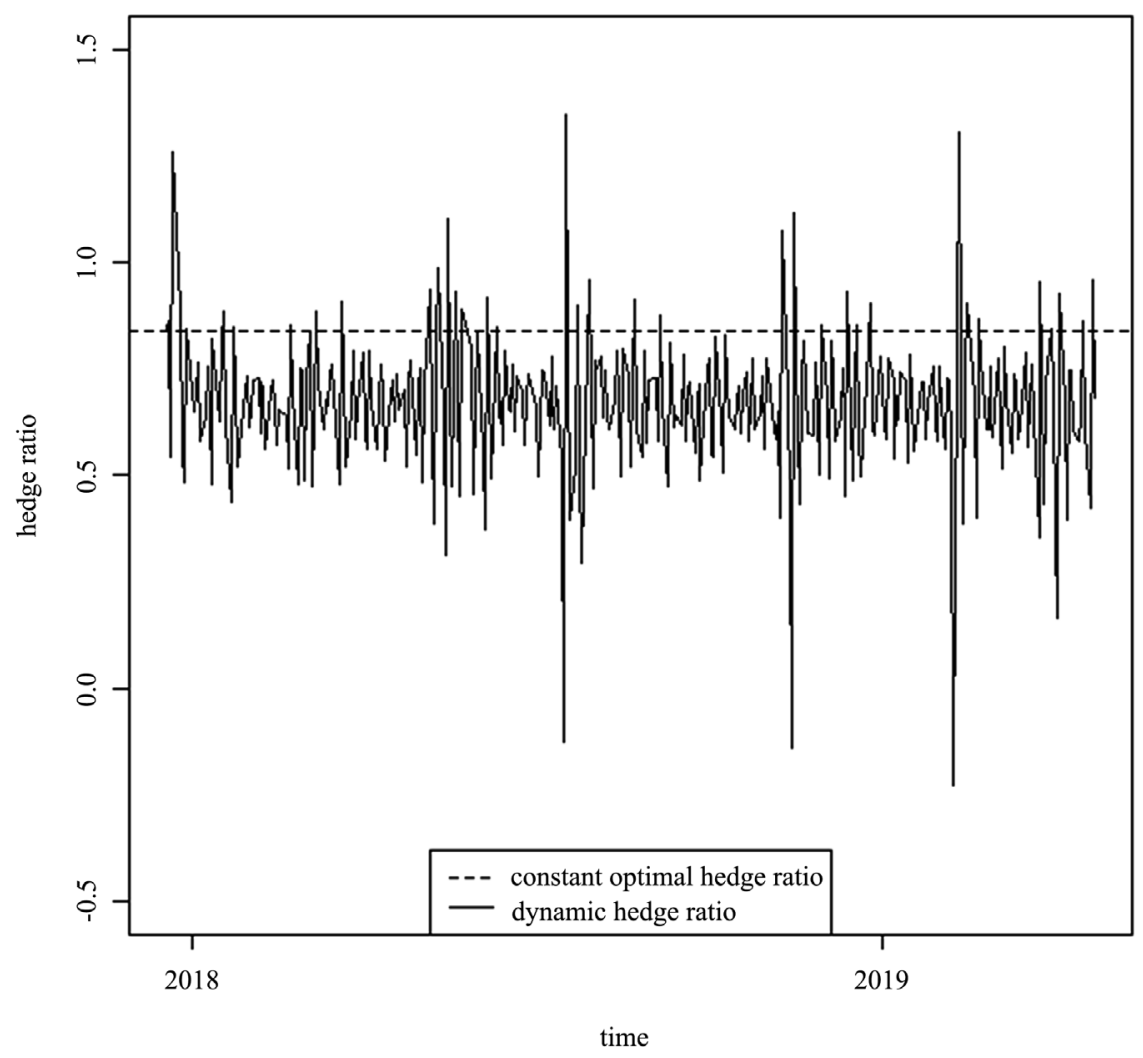

Figure 3. Constant optimal hedge ratio and dynamic hedge ratio.

Table 3. Variances of hedged portfolio and risk reduction.

\begin{tabular}{ccc}
\hline & $\operatorname{Var}\left(\Delta s_{t}-h_{t} \Delta f_{t}\right)$ & Risk reduction (\%) \\
\hline Naïve hedge $\left(h_{t}=1\right)$ & $92,114.42$ & $57.0 \%$ \\
Constant optimal hedge $\left(h_{t}=\beta\right)$ & 87571.7 & $59.1 \%$ \\
Dynamic hedge $\left(h_{t}=\varphi_{t}\right)$ & $87,201.47$ & $59.3 \%$ \\
\hline
\end{tabular}

compared by computing the percentage changes of the variance of the hedged portfolio to the variance of the underlying spot without hedging. It is obvious from the risk reduction of 59.3\%, using the bivariate BEKK-GJR-GARCH model, that it performed best among the three methods.

Table 4 shows the descriptive statistics of the prices and returns in the four exchanges. The number of observations varies across the four exchanges, because the data in the different exchanges began to be available on different dates. At first glance, we observe that the standard deviations and ranges of the Bitcoin prices in the four exchanges are large, which shows that the movement in Bitcoin is quite volatile. The Bitcoin returns also share similarities in their large kurtosis, which means that their distribution could be leptokurtic with fat tails. The skewnesses of the returns are all less than zero, which means that negative returns are obtained more frequently. 
As shown in Table 5, the dates and observations of the Bitcoin returns from the four exchanges are divided into three groups, from the period before BRR launched, from the transition period, and from the period after BTC was listed. Table 6 shows the means and variances of the Bitcoin returns in the four exchanges. Roughly speaking, the variances tend to decrease slightly from period to period.

Table 7 reports the estimated coefficients of $a$ and $b$ in Equation (17). All the coefficients are statistically significant.

Table 8 displays the results of the two-sample $t$ statistics for $a$ and $b$ in the three cases: the period before BRR launched vs. the transition period, the transition period vs. the period after BTC was listed, and the period before BRR launched vs. the period after BTC was listed. The results show that $a$ and $b$ are significantly different across different periods. The findings confirm our hypothesis that the volatility of Bitcoin returns would change significantly from period to period.

Table 4. Price and return from four exchanges.

\begin{tabular}{cccccccccc}
\hline & \multicolumn{2}{c}{ Bitstamp (BSTP) } & \multicolumn{2}{c}{ Coinbase (COIN) } & \multicolumn{2}{c}{ itBit (IBIT) } & \multicolumn{2}{c}{ Kraken (KRKN) } \\
\cline { 2 - 9 } & Price (USD) & Return & Price (USD) & Return & Price (USD) & Return & Price (USD) & Return \\
\hline Mean & 1861.113 & 0.002216968 & 2574.643 & 0.001878192 & 2605.654 & 0.001411116 & 2565.401 & 0.001883923 \\
Standard deviation & 3082.401 & 0.05067167 & 3391.843 & 0.04518369 & 3406.15 & 0.04159618 & 3369.981 & 0.04450417 \\
Median & 442.18 & 0.001650525 & 666.66 & 0.00166824 & 673.96 & 0.001548245 & 668.435 & 0.001407714 \\
Min & 2.24 & -0.663948 & 123.21 & -0.5838671 & 187.59 & -0.2832743 & 122 & -0.2915184 \\
Max & $19,100.07$ & 0.4455433 & 19450.01 & 0.3006408 & 19195 & 0.2483466 & 19388 & 0.3536184 \\
Range & $19,097.83$ & 1.109491 & 19326.8 & 0.8845079 & 19007.41 & 0.5316209 & 19266 & 0.6451368 \\
Skewness & 2.244372 & -1.382001 & 1.824436 & -1.119864 & 1.785243 & -0.178184 & 1.802354 & -0.03857741 \\
Kurtosis & 5.245956 & 24.44747 & 3.351554 & 20.63693 & 3.126098 & 6.355222 & 3.207212 & 8.098131 \\
Standard error & 58.16886 & 0.00095641 & 75.41153 & 0.001004827 & 76.62496 & 0.000935987 & 74.94399 & 0.00098996 \\
Observations & 2808 & 2807 & 2023 & 2022 & 1976 & 1975 & 2022 & 2021 \\
\hline
\end{tabular}

Bitstamp data period is from 2011/08/18 to $2019 / 04 / 25$. Coinbase data period is from 2013/10/06 to 2019/04/25. itBit data period is from 2013/11/11 to $2019 / 04 / 25$. Kraken data period is from $2013 / 10 / 06$ to $2019 / 04 / 25$.

Table 5. Dates and observations of Bitcoin return from four exchanges.

\begin{tabular}{ccccc}
\hline $\begin{array}{c}\text { Exchange } \\
\text { Name }\end{array}$ & $\begin{array}{c}\text { Total data period } \\
\text { (Observations) }\end{array}$ & $\begin{array}{c}\text { Period before BRR launched } \\
\text { (Observations) }\end{array}$ & $\begin{array}{c}\text { Transition period } \\
\text { (Observations) }\end{array}$ & $\begin{array}{c}\text { Period after BTC listed } \\
\text { (Observations) }\end{array}$ \\
\hline $\begin{array}{c}\text { Bitstamp } \\
\text { (BSTP) }\end{array}$ & $\begin{array}{c}2011 / 08 / 19-2019 / 04 / 25 \\
(2807)\end{array}$ & $\begin{array}{c}2011 / 08 / 19-2016 / 11 / 13 \\
(1914)\end{array}$ & $\begin{array}{c}2016 / 11 / 14-2017 / 12 / 17 \\
(399)\end{array}$ & $\begin{array}{c}2017 / 12 / 18-2019 / 04 / 25 \\
(494)\end{array}$ \\
Coinbase & $2013 / 10 / 07-2019 / 04 / 25$ & $2013 / 10 / 07-2016 / 11 / 13$ & $2016 / 11 / 14-2017 / 12 / 17$ & $2017 / 12 / 18-2019 / 04 / 25$ \\
$($ COIN) & $(2022)$ & $(1129)$ & $(399)$ & $(494)$ \\
itBit & $2013 / 11 / 12-2019 / 04 / 25$ & $2013 / 11 / 12-2016 / 11 / 13$ & $2016 / 11 / 14-2017 / 12 / 17$ & $2017 / 12 / 18-2019 / 04 / 25$ \\
$($ IBIT $)$ & $(1975)$ & $(1095)$ & $(399)$ & $(481)$ \\
Kraken & $2013 / 10 / 07-2019 / 04 / 25$ & $2013 / 10 / 07-2016 / 11 / 13$ & $2016 / 11 / 14-2017 / 12 / 17$ & $2017 / 12 / 18-2019 / 04 / 25$ \\
$($ KRKN) & $(2021)$ & $(1129)$ & $(399)$ & $(493)$ \\
\hline
\end{tabular}


Table 6. Means and variances for Bitcoin returns in the four exchanges.

\begin{tabular}{ccccccc}
\hline & \multicolumn{2}{c}{ Period before BRR launched } & \multicolumn{2}{c}{ Transition period } & \multicolumn{2}{c}{ Period after BTC listed } \\
\hline Exchange Name & Mean & Variance & Mean & Variance & Mean & Variance \\
Bitstamp (BSTP) & 0.002176592 & 0.002869119 & 0.0082446 & 0.001925276 & -0.002495066 & 0.001875019 \\
Coinbase (COIN) & 0.001543808 & 0.002124158 & 0.008316514 & 0.002006074 & -0.002557783 & 0.001836004 \\
itBit (IBIT) & 0.000668537 & 0.001610118 & 0.008275029 & 0.001882028 & -0.002592162 & 0.0018289 \\
Kraken (KRKN) & 0.001551391 & 0.002025986 & 0.008242422 & 0.001990083 & -0.002500686 & 0.001824706 \\
\hline
\end{tabular}

Table 7. Estimates from the variance equation for three periods $h_{t}=c_{0}+a r_{t-1}^{2}+b h_{t-1}$.

\begin{tabular}{|c|c|c|c|c|c|c|c|c|c|c|c|c|}
\hline \multirow{3}{*}{$\begin{array}{l}\text { Exchange } \\
\text { Name }\end{array}$} & \multicolumn{4}{|c|}{ Period before BRR launched } & \multicolumn{4}{|c|}{ Transition period } & \multicolumn{4}{|c|}{ Period after BTC listed } \\
\hline & \multicolumn{2}{|c|}{$a$} & \multicolumn{2}{|c|}{$b$} & \multicolumn{2}{|c|}{$a$} & \multicolumn{2}{|l|}{$b$} & \multicolumn{2}{|c|}{$a$} & \multicolumn{2}{|l|}{$b$} \\
\hline & coefficient & $\operatorname{Pr}(>|t|)$ & coefficient & $\operatorname{Pr}(>|t|)$ & coefficient & $\operatorname{Pr}(>|t|)$ & coefficient & $\operatorname{Pr}(>|t|)$ & coefficient & $\operatorname{Pr}(>|t|)$ & coefficient & $\operatorname{Pr}(>|t|)$ \\
\hline $\begin{array}{l}\text { Bitstamp } \\
\text { (BSTP) }\end{array}$ & 0.114995 & 0 & 0.884005 & 0 & 0.223931 & 0.000001 & 0.775069 & 0 & 0.057275 & 0.000273 & 0.907070 & 0 \\
\hline $\begin{array}{c}\text { Coinbase } \\
\text { (COIN) }\end{array}$ & 0.154797 & 0 & 0.844203 & 0 & 0.242630 & 0.000001 & 0.756370 & 0 & 0.057233 & 0.000270 & 0.907398 & 0 \\
\hline $\begin{array}{c}\text { itBit } \\
\text { (IBIT) }\end{array}$ & 0.15600 & 0 & 0.84300 & 0 & 0.217562 & 0 & 0.781438 & 0 & 0.061156 & 0.000412 & 0.898401 & 0 \\
\hline $\begin{array}{l}\text { Kraken } \\
(\text { KRKN) }\end{array}$ & 0.119652 & 0 & 0.879348 & 0 & 0.232174 & 0 & 0.766826 & 0 & 0.063274 & 0.000422 & 0.894515 & 0 \\
\hline
\end{tabular}

Table 8. Two-sample statistics $t_{d}$ and $p$-values for $a$ and $b, t_{d}=\frac{\left(\bar{x}_{\text {before }}-\bar{x}_{\text {after }}\right)-\left(\mu_{\text {before }}-\mu_{\text {after }}\right)}{\sqrt{\left(\frac{\left(n_{\text {before }}-1\right) s_{\text {before }}^{2}+\left(n_{\text {after }}-1\right) s_{\text {after }}^{2}}{n_{\text {before }}+n_{\text {after }}-2}\right)\left(\frac{1}{n_{\text {before }}}+\frac{1}{n_{\text {after }}}\right)}}$.

\begin{tabular}{ccccc}
\hline Period (before/after) & $t$ & p-value & $t$ & p-value \\
\hline Period before BRR launched/Transition period & -7.5417 & 0.0002818 & 7.5417 & 0.0002819 \\
Transition period/Period after BTC listed & 30.124 & $8.879 \mathrm{E}-08$ & -20.944 & $7.718 \mathrm{E}-07$ \\
Period before BRR launched/Period after BTC listed & 6.8811 & 0.0004647 & -3.4114 & 0.01429 \\
\hline
\end{tabular}

$p$-value in $95 \%$ confidence interval is significant.

\section{Conclusion}

In this paper, we investigated the Bitcoin and Bitcoin futures markets to clarify their interrelationship. There were two main tasks in our study. One was to compare the optimal hedge ratios using three different hedge strategies, the naïve hedge, the ordinary least squares (OLS) method, and dynamic hedging with the bivariate BEKK-GJR-GARCH model. The other was to test whether the volatility of Bitcoin would be significantly different before and after Bitcoin futures launched.

We began by using the data of the underlying spot, BRR, and the Bitcoin futures price, BTC, from the Thomson Reuters Eikon (Eikon) database. We compared the performance of the hedged portfolio constructed using these three 
different hedge methods. Our results showed that dynamic hedging with the bivariate BEKK-GJR-GARCH model was the most effective strategy with around $59 \%$ of risk reduction compared to no hedge.

Then we used the data from the Bloomberg database to obtain the Bitcoin prices from the four exchanges, Bitstamp, Coinbase, itBit, and Kraken. To examine whether the volatility structure of the Bitcoin price returns would change across different periods, we divided our data into three groups: the period before BRR launched, the transition period, and the period after BTC was listed. By applying the GARCH $(1,1)$ model and the two-sample $t$ test proposed by Harnett and Soni (1991), we found that the volatility of the Bitcoin price returns demonstrated significant changes across different periods. Evidence could be found in cases of the period before BRR launched vs. the transition period, the transition period vs. the period after BTC was listed, and the period before BRR launched vs. the period after BTC was listed.

The results of our two tasks correspond to each other quite well and could be treated as each other's robustness test. Since we proved that hedging with Bitcoin futures could reduce the Bitcoin market risk to a certain extent, there is no doubt that we observed that the volatility structure of the Bitcoin price returns after the introduction of the Bitcoin futures resulted in significant changes, not only during the transition period but also during the period before BRR launched. Similarly, the observations of volatility changes after the introduction of the Bitcoin futures could justify the necessity and effectiveness of Bitcoin futures in hedging the Bitcoin price.

As for the further study, we suggest that we should investigate the influence of the launch of Bitcoin futures options on Bitcoin and Bitcoin futures. Bitcoin futures options launched on the CME on 13 Jan. 2020. We could extend our study once we get adequate data.

\section{Conflicts of Interest}

The authors declare no conflicts of interest regarding the publication of this paper.

\section{References}

Aftab, H., Beg, R., Sun, S., \& Zhou, Z. (2019). Testing and Predicting Volatility Spillover-A Multivariate GJR-GARCH Approach. Theoretical Economics Letters, 9, 83-99. https://doi.org/10.4236/tel.2019.91008

Akgiray, V. (1989). Conditional Heteroscedasticity in Time Series of Stock Returns: Evidence and Forecasts. Journal of Business, 62, 55-80. https://doi.org/10.1086/296451

Baillie, R. T., \& Myers, R. J. (1991). Bivariate GARCH Estimation of the Optimal Commodity Futures Hedge. Journal of Applied Econometrics, 6, 109-124. https://doi.org/10.1002/jae.3950060202

Bouri, E., Molnár, P., Azzi, G., Roubaud, D., \& Hagfors, L. I. (2017). On the Hedge and Safe Haven Properties of Bitcoin: Is It Really More than a Diversifier? Finance Research Letters, 20, 192-198. https://doi.org/10.1016/j.frl.2016.09.025 
Cecchetti, S. G., Cumby, R. E., \& Figlewski, S. (1988). Estimation of the Optimal Futures Hedge. The Review of Economics and Statistics, 70, 623-630. https://doi.org/10.2307/1935825

Corbet, S., Lucey, B., Peat, M., \& Vigne, S. (2018). Bitcoin Futures-What Use Are They? Economics Letters, 172, 23-27. https://doi.org/10.1016/j.econlet.2018.07.031

Dyhrberg, A. H. (2016). Hedging Capabilities of Bitcoin. Is It the Virtual Gold? Finance Research Letters, 16, 139-144. https://doi.org/10.1016/j.frl.2015.10.025

Harnett, D. L., \& Soni, A. (1991). Statistical Methods for Business and Economics (4th ed.). Reading, MA: Addison-Wesley.

Hattori, T., \& Ishida, R. (2018). Did the Introduction of Bitcoin Futures Crash the Bitcoin Market at the End of 2017. https://doi.org/10.2139/ssrn.3307977

Hung, M. W., \& So, L. C. (2009). New Insights into India's Single Stock Futures Markets. Review of Futures Markets, 17, 335-355.

Hung, M. W., Lee, C. F., \& So, L. C. (2005). Hedging with Foreign-Listed Single Stock Futures. Advances in Quantitative Analysis of Finance and Accounting, 2, 129-151. https://doi.org/10.1142/9789812701213_0008

Kroner, K. F., \& Sultan, J. (1993). Time-Varying Distributions and Dynamic Hedging with Foreign Currency Futures. Journal of Financial and Quantitative Analysis, 28, 535-551. https://doi.org/10.2307/2331164

Kurka, J. (2019). Do Cryptocurrencies and Traditional Asset Classes Influence Each Other? Finance Research Letters, 31, 38-46. https://doi.org/10.1016/j.frl.2019.04.018

Liu, R., Wan, S., Zhang, Z., \& Zhao, X. (2019). Is the Introduction of Futures Responsible for the Crash of Bitcoin? Finance Research Letters, 34, Article ID: 101259.

Park, T. H., \& Switzer, L. N. (1995). Bivariate GARCH Estimation of the Optimal Hedge Ratios for Stock Index Futures: A Note. Journal of Futures Markets, 15, 61-67. https://doi.org/10.1002/fut.3990150106

Rahman, S. (2001). The Introduction of Derivatives on the Dow Jones Industrial Average and Their Impact on the Volatility of Component Stocks. Journal of Futures Markets: Futures, Options, and Other Derivative Products, 21, 633-653.

https://doi.org/10.1002/fut.1702 